\title{
Manganese transporter Slc39a14 deficiency revealed its key role in maintaining manganese homeostasis in mice
}

\author{
Yongjuan Xin ${ }^{1,8}$, Hong Gao ${ }^{2,8}$, Jia Wang ${ }^{1,8}$, Yuzhen Qiang ${ }^{1}$, Mustapha Umar Imam ${ }^{1}$, Yang Li $^{1}$, \\ Jianyao Wang ${ }^{1}$, Ruochen Zhang ${ }^{1}$, Huizhen Zhang ${ }^{1}$, Yingying $\mathrm{Yu}^{2}$, Hao Wang ${ }^{2}$, Haiyang Luo ${ }^{3}$, Changhe Shi $^{3}$, \\ Yuming $\mathrm{Xu}^{3}$, Shintaro Hojyo ${ }^{4}$, Toshiyuki Fukada ${ }^{5,6,7}$, Junxia Min², Fudi Wang ${ }^{1,2, *}$ \\ ${ }^{1}$ Department of Nutrition, Precision Nutrition Innovation Center, School of Public Health, Zhengzhou University, Zhengzhou, \\ China; ${ }^{2}$ Department of Nutrition, Nutrition Discovery Innovation Center, Institute of Nutrition and Food Safety, School of Public \\ Health, The First Affiliated Hospital, Institute of Translational Medicine, School of Medicine, Collaborative Innovation Center \\ for Diagnosis and Treatment of Infectious Diseases, Zhejiang University, Hangzhou, China, ${ }^{3}$ Department of Neurology, The First \\ Affiliated Hospital of Zhengzhou University, Zhengzhou University, Zhengzhou, China; ${ }^{4}$ Osteoimmunology, Deutsches \\ Rheuma-Forschungszentrum, Berlin, Germany; ${ }^{5}$ Molecular and Cellular Physiology, Faculty of Pharmaceutical Sciences, \\ Tokushima Bunri University, Tokushima, Japan; ${ }^{6}$ Division of Pathology, Department of Oral Diagnostic Sciences, School of \\ Dentistry, Showa University, Shinagawa, Japan; ${ }^{7}$ RIKEN Center for Integrative Medical Sciences, Yokohama, Japan
}

SLC39A14 (also known as ZIP14), a member of the SLC39A transmembrane metal transporter family, has been reported to mediate the cellular uptake of iron and zinc. Recently, however, mutations in the SLC39A14 gene have been linked to manganese (Mn) accumulation in the brain and childhood-onset parkinsonism dystonia. It has therefore been suggested that SLC39A14 deficiency impairs hepatic Mn uptake and biliary excretion, resulting in the accumulation of $\mathrm{Mn}$ in the circulation and brain. To test this hypothesis, we generated and characterized global Slc39a14-knockout $\left(\right.$ Slc39a14 $\left.{ }^{-1-}\right)$ mice and hepatocyte-specific Slc39a14-knockout $\left(S l c 39 a 14^{f l f l} ; A l b-C r e^{+}\right)$mice. Slc39a14 ${ }^{-1-}$ mice develop markedly increased Mn concentrations in the brain and several extrahepatic tissues, as well as motor deficits that can be

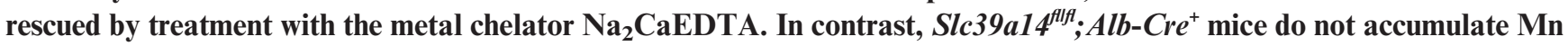
in the brain or other extrahepatic tissues and do not develop motor deficits, indicating that the loss of Slc39a14 expression selectively in hepatocytes is not sufficient to cause Mn accumulation. Interestingly, Slc39a14 ${ }^{\text {flf }}$; $\mathrm{Alb}$-Cre $\mathrm{Cr}^{+}$mice fed a high Mn diet have increased Mn levels in the serum, brain and pancreas, but not in the liver. Taken together, our results indicate that Slc39a14 ${ }^{-I-}$ mice develop brain Mn accumulation and motor deficits that cannot be explained by a loss of Slc39a14 expression in hepatocytes. These findings provide insight into the physiological role that SLC39A14 has in maintaining Mn homeostasis. Our tissue-specific Slc39a14-knockout mouse model can serve as a valuable tool for further dissecting the organ-specific role of SLC39A14 in regulating the body's susceptibility to Mn toxicity.

Keywords: Slc39a14; Zip14; manganese; metal homeostasis; parkinsonism dystonia

Cell Discovery (2017) 3, 17025; doi:10.1038/celldisc.2017.25; published online 18 July 2017

\section{Introduction}

In the body, metal homeostasis is a complex process involving multiple transporters that are tightly regulated by the levels of their substrates and/or other environmental conditions. The brain is particularly

\footnotetext{
${ }^{8}$ These authors contributed equally to this work. *Correspondence: Fudi Wang

Tel: +86 371 67781737; Fax: +86 37167781737

E-mail: fwang@zju.edu.cn

Received 5 April 2017; accepted 2 July 2017
}

susceptible to the toxic effects of metals, and metals readily accumulate in the brain in the event of impaired metal homeostasis [1-3]. Manganese (Mn), an essential element for humans, is normally present in the brain, bone, liver, pancreas and kidney, and $\mathrm{Mn}$ imbalance has been linked to impaired brain functioning [4-7]. To date, several transporter proteins have been identified as having a role in maintaining Mn levels, including divalent metal ion transporter-1 (DMT1) [8-11], ferroportin (Fpn1) [12], SLC39A8 (also known as ZIP8) [13, 14], SLC30A10 (also known as ZnT10) 
[15-17] and SLC39A14 (also known as ZIP14) [4]. However, the precise molecular mechanisms that underlie Mn homeostasis are poorly understood.

The liver has a key role in maintaining Mn homeostasis in the body [18]. In patients, mutations in the hepatic metal ion transporter SLC39A8 have been linked to low blood Mn levels as well as several other human phenotypic traits. Recently, Lin et al. showed that both Slc39a8-knockout mice and mice in which Slc39a8 expression is deleted specifically in the liver develop significantly decreased tissue Mn levels [13]. Conversely, SLC30A10 is a Mn exporter that replenishes serum Mn from tissue stores [19, 20]. Dietary Mn absorbed in the intestines is transported in the plasma by gamma globulin and albumin, although a small fraction of $\mathrm{Mn}$ is transported as a complex with transferrin and is taken up in neurons primarily via transferrin receptor 1 (TfR 1 , encoded in humans by the $T F R C$ gene) $[5,21]$ and possibly other cells that express high levels of TfR1 [22]. In hepatocytes, Mn is largely sequestered in the mitochondria, where it performs numerous biological functions as a co-factor for many enzymes, including superoxide dismutase, arginase and glycosyltransferases $[23,24]$. At the systemic level, Mn concentration is tightly regulated by the coordinated absorption and excretion of $\mathrm{Mn}$ [5]. Mn is excreted primarily via biliary and pancreatic secretion into the caudal sections of the gastrointestinal tract $[25,26]$, which help regulate the body's Mn levels by adjusting the rate of elimination [27].

SLC39A14 was first discovered for its role in the uptake of zinc into the liver in response to acute inflammation and infection [28]. Mutations in SLC39A14 can induce parkinsonism dystonia-like (PD-like) symptoms as a result of $\mathrm{Mn}$ accumulation in various brain structures, particularly the globus pallidus and striatum [4]. Similarly, mutations in other Mn transporters such as SLC30A10 can also induce Mn neurotoxicity and its related symptoms [15, 29, 30]. However, despite the established role of Mn homeostasis in maintaining health, the tissue-specific in vivo role of Mn transporters has not been clearly defined.

Here, we report that global Slc39a14-knockout $\left(\right.$ Slc39al4 $\left.{ }^{-1-}\right)$ mice and hepatocyte-specific Slc39al4knockout $\left(\right.$ Slc39al4 ${ }^{\text {fllf }}$; Alb-Cre ${ }^{+}$) mice have distinct Mn-related phenotypes and tissue metal distributions. Specifically, although Slc39a14 ${ }^{-l-}$ mice recapitulate the hypermanganesemia that occurs in patients with PDlike syndrome [4], no Mn accumulation was observed in the brain or other tissues of Slc39a14 ${ }^{\text {fllff }}$; Alb-Cre $e^{+}$ mice, which have considerably lower hepatic Mn levels. These findings provide new insight into the physiological role of SLC39A14 as a major Mn importer in the liver, and shed new light on the clinical effects of disrupting Mn homeostasis.

\section{Results}

\section{Slc39a14 $4^{-1-}$ mice develop progressive behavioral and motor deficits}

Consistent with previous reports [31, 32], our homozygous Slc39a14-knockout $\left(\right.$ Slc39al4 $\left.{ }^{-1-}\right)$ mice are viable and have no discernible morphological abnormalities at birth. However, by 4 weeks of age, these mice begin to show signs of progressive random torticollis and motor deficits (Figure 1a; Supplementary Movies S1-S5). Compared with wildtype littermates, Slc39a14 ${ }^{-1-}$ mice have lower body weight beginning at 8 weeks of age (Figure 1b). By six months of age, Slc39a14 ${ }^{-/}$mice began to show signs of dystonia with a progressive inability to coordinate their motor activity (Figure 1c-i); these symptoms are similar to the PD-like motor disability in patients with a mutation in SLC39A14 [4].

To further investigate the neurologically induced behavioral phenotypes in Slc39a14 ${ }^{-1-}$ mice, we used the balance beam test $[33,34]$, the accelerating rotarod test $[35,36]$ and CatWalk gait analysis [37-39] to evaluate the animals' walking ability and balance. In the bal-

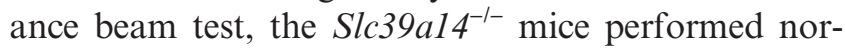
mally until 11 weeks of age, after which they began to show neurological deficits in terms of taking longer to cross the beam (Figure 1c). By 15 weeks of age, the Slc39a14 $4^{-1-}$ mice were unable to complete the balance beam test, as they were unable to stay on to the beam.

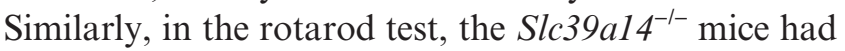
significantly lower drop speed and running time compared with wild-type littermates; these deficits progressively worsened from 13 weeks of age to 24 weeks of age, the oldest age tested (Figure 1d-f). To assess gait and locomotion, we used the CatWalk test to visualize the animals' footprints, and we calculated the print dimensions as well as the time and distance between footfalls. As shown in Figure 1g, the Slc39a14 ${ }^{-1-}$ mice showed an irregular footprint patterns. The Slc39a14 ${ }^{-1-}$ mice developed motor deficits beginning at 16 weeks of age, with significant differences in duration of running time (Figure 1h), average running speed (Figure 1i), time of right forelimb (RF) stand (Figure 1j), right forelimb (RF) and left hindlimb (LH) swing speed (Figure $1 \mathrm{k}$ and 1 ) compared with wild-type littermates. Taken together, these results show that Slc39a14 ${ }^{-1-}$ mice develop progressive motor deficits as early as 12 weeks of age. 
a

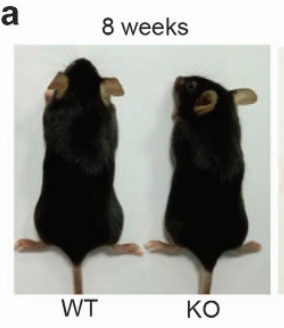

c

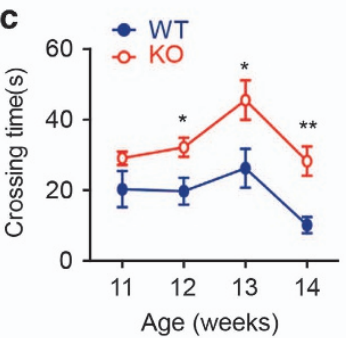

g
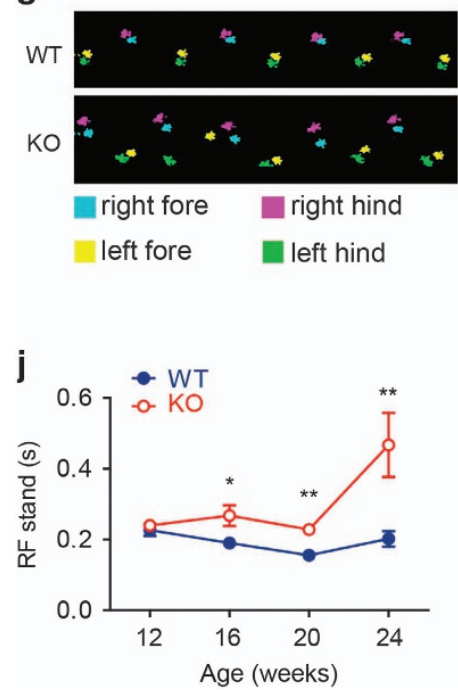

d
24 weeks
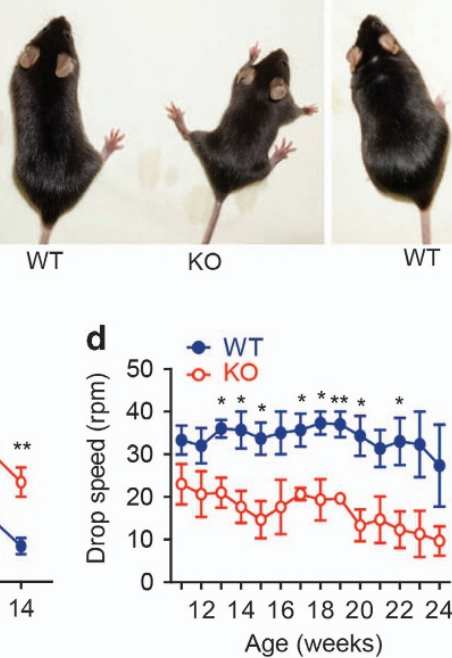

h

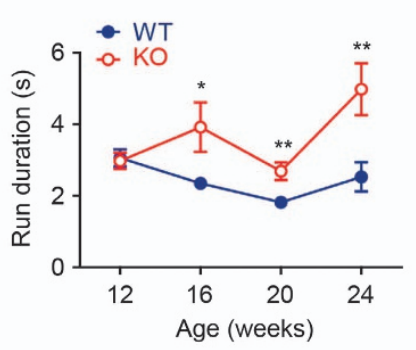

$\mathbf{k}$

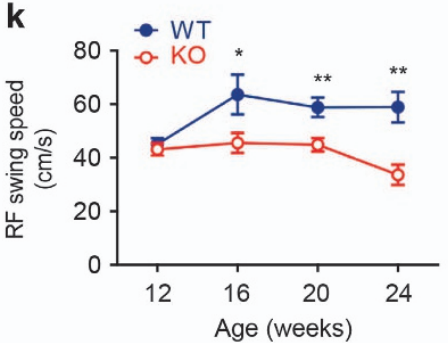

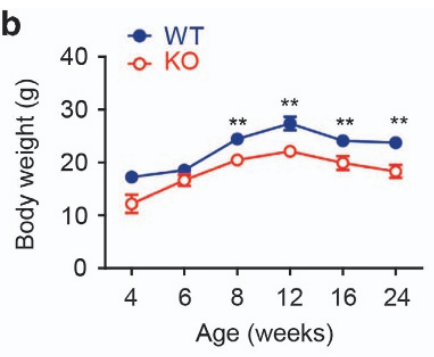
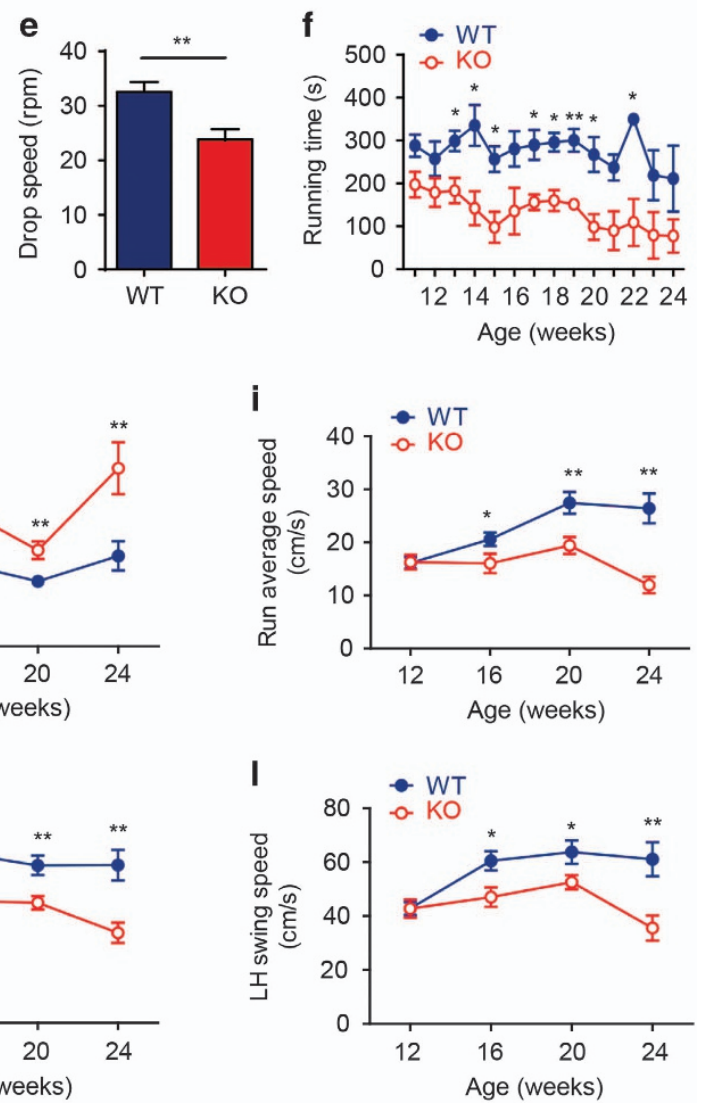

Figure $1 \mathrm{~S} / \mathrm{c} 39 \mathrm{a} 14^{-/-}$mice develop abnormal behavioral and motor phenotype. (a) Representative images of a wild-type (WT) and S/c39a14 ${ }^{-/-}$mouse (KO) at 8, 24 and 48 weeks of age. (b) Body weight of WT and KO littermates ( $n \geqslant 4$ mice/group). (c) Balance beam test results of WT and KO mice ( $n=3$ mice/group). (d-f) Rotarod test results of WT and KO mice ( $n=3$ mice/ group). (e) The drop speed of WT and KO mice measured at 20 weeks of age ( $n=19$ female mice and 20 male mice). (g) CatWalk analysis of a WT and KO mouse. Blue and purple represent the right forelimb (RF) and hindlimb (RH), respectively, and yellow and green represent the left forelimb (LF) and hindlimb (LH), respectively. (h-l) Analyses of CatWalk test results for WT and KO mice ( $n=3$ mice/group). RF stands for right forelimb, LH stands for left hindlimb. ${ }^{\star} P<0.05$ and ${ }^{* *} P<0.01$, unpaired Student's $t$-test.

Loss of Slc39a14 expression leads to Mn accumulation

Slc39a14 has been reported to transport several metals, including Mn [4], zinc (Zn) [31] and iron (Fe) [40]. Therefore, we used inductively coupled plasma mass spectrometry (ICP-MS) to measure the levels of various metals in Slc39al4 ${ }^{-1-}$ and wild-type mice [41-43]. Interestingly, compared with age-matched wild-type controls, at 48 weeks of age the Slc39al $4^{-1-}$ mice had significantly higher levels of $\mathrm{Mn}$ in a wide range of tissues, including the serum, brain, kidney, lung, heart and spleen (Figure 2a); Mn levels in the liver and intestine were similar between wild-type and Slc39al4 ${ }^{-1-}$ mice. We found no significant differences between wild-type and Slc39a14 ${ }^{-1-}$ mice with respect to $\mathrm{Fe}, \mathrm{Zn}$ or $\mathrm{Cu}$ in any tissues (Figure $2 \mathrm{~b}-\mathrm{d}$ ), with the exception of a slight yet significant increase in serum $\mathrm{Fe}$ 
a

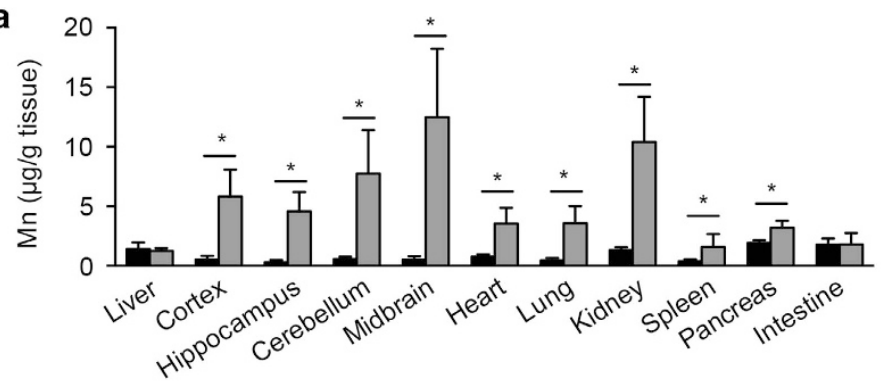

b

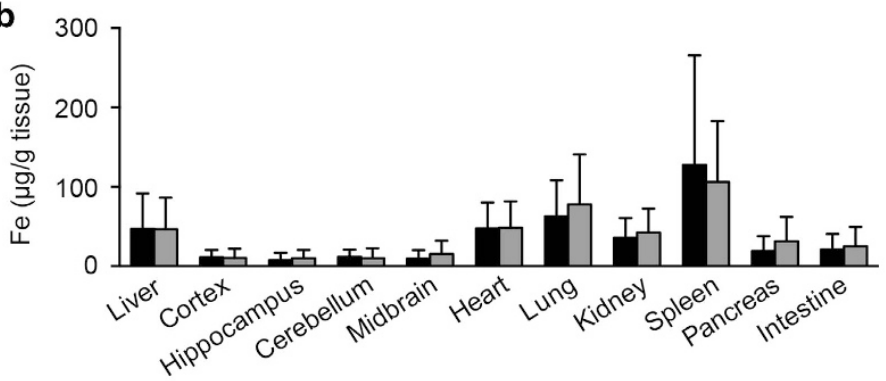

c

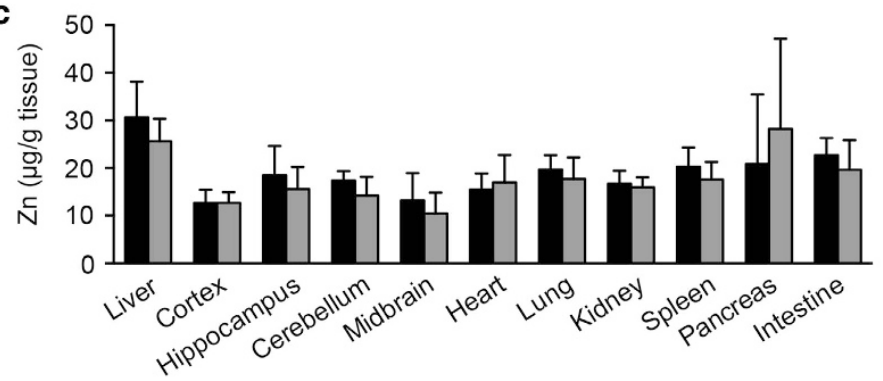

d

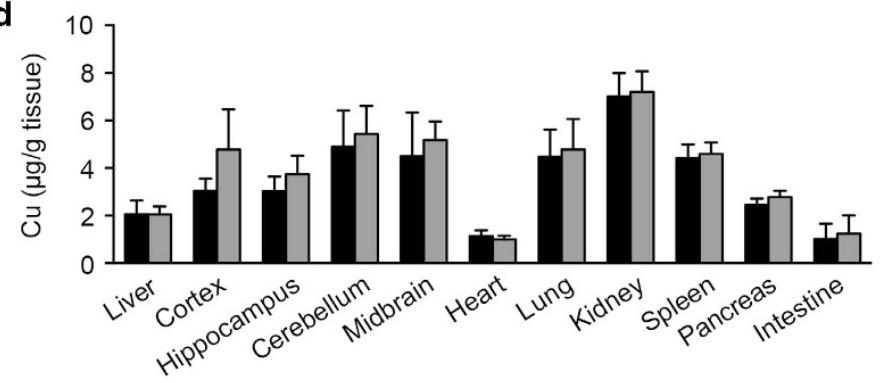

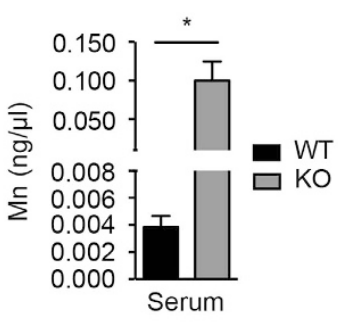
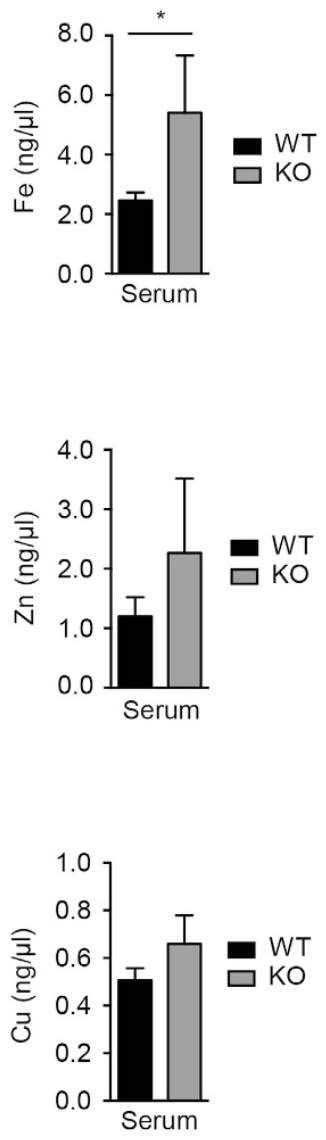
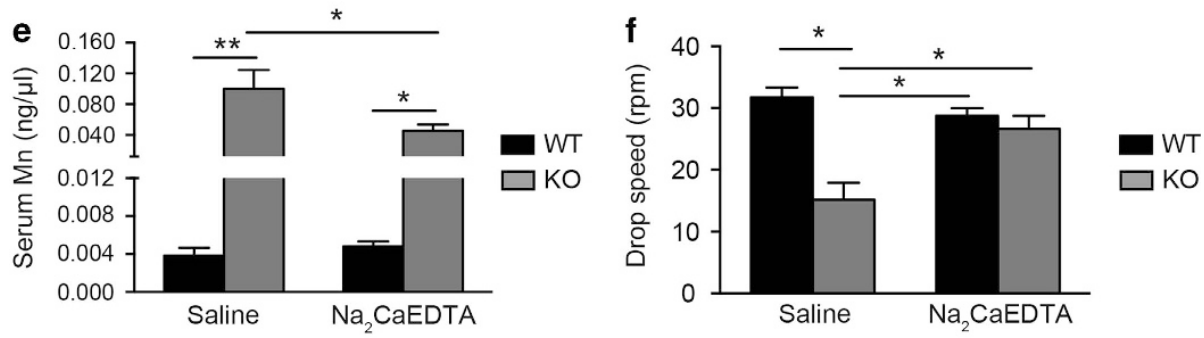

Figure 2 S/c39a14 $4^{-/-}$mice develop Mn accumulation in a variety of tissues. (a-d) Mn (a), Fe (b), Zn (c) and Cu (d) levels were measured in the indicated tissues of wild-type (WT) and S/c39a14 ${ }^{-/}$(KO) mice at $>24$ weeks of age using ICP-MS $(n=4$ mice/ group). In a, note the break in the $y$-axis for serum Mn. ${ }^{*} P<0.05$, unpaired Student's $t$-test. (e) Serum Mn levels in S/c39a14 ${ }^{-/}$ mice treated for four weeks with $\mathrm{Na}_{2} \mathrm{CaEDTA}(370 \mathrm{mg} / \mathrm{kg}$ body weight) or saline ( $n=8-12$ mice/group, $5 \mathrm{month}$ of age). (f) Rotarod test results of S/c39a14 ${ }^{-/-}$mice treated for four weeks with $\mathrm{Na}_{2} \mathrm{CaEDTA}$ or saline $(n=8-12$ mice/group, 5 month of age). In $\mathbf{e}$ and $\mathbf{f},{ }^{*} P<0.05$ and ${ }^{* *} P<0.01$, one-way ANOVA with Tukey's post hoc test. 
levels (Figure 2b). Taken together, these data indicate that Slc39a14 is predominantly a Mn transporter.

As early as 8 weeks of age, Slc39a14 $4^{-/-}$mice have brain Mn levels that are $\sim 10$-fold higher than agematched wild-type control mice. We therefore tested whether the effects of $\mathrm{Mn}$ accumulation could be reduced by treating mice with the metal chelator $\mathrm{Na}_{2} \mathrm{CaEDTA}$. At 5 months of age, we treated wildtype and Slc39a14 ${ }^{-1-}$ mice with $\mathrm{Na}_{2} \mathrm{CaEDTA}$ for 4 weeks using a standard therapeutic protocol [44, 45]. Chelation therapy had no effect on serum Mn levels (Figure 2e) or rotarod performance (Figure 2f) in wildtype mice; however, in Slc39a14 $4^{-1-}$ mice, $\mathrm{Na}_{2} \mathrm{CaEDTA}$ treatment significantly reduced serum $\mathrm{Mn}$ levels (from

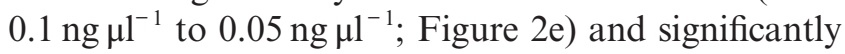
improved performance on the rotarod test (Figure 2f).

\section{Loss of Slc39a14 expression alters the expression of various Mn transporters in several tissues}

The expression of many metal transporters is highly dynamic and can be regulated by the concentration of their respective substrates [46]. In the absence of Slc39al4 expression, other transporters (including Slc30a10, Fpn1, Dmt1, Slc39a8 and Mn citrate shuttle), glutamate receptors and calcium channels may have a compensatory role in maintaining normal hepatic Mn levels and intestinal Mn absorption [46]. We hypothesized that any differences in the expression of these transporters may contribute to the altered levels of $\mathrm{Mn}$ and the other metals observed in the Slc39a14 ${ }^{-1-}$ mice. We therefore measured the effects of deleting Slc39a14 expression on the expression of six genes that encode Mn transporters (Slc39a8, Slc13a5, Slc2a4, Dmt1, Fpn1 and Slc30a10) in the liver, cortex, hippocampus, cerebellum, heart, kidney, spleen, pancreas and intestine (Figure 3a-i). We found that some genes are upregulated in some tissues and downregulated in other tissues, suggesting a highly dynamic regulatory process. Notably, the expression of Mn importers, including Slc2a4, was

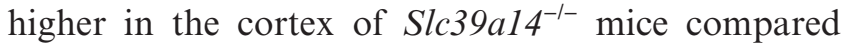
with wild-type mice (Figure 3b), whereas the $\mathrm{Mn}$ exporters Slc30alO and FpnI were downregulated in the kidney. In the liver (Figure 3a), the expression of Dmt1 and Slc30alO was significantly increased in the Slc39a14 ${ }^{-1-}$ mice, whereas the expression of Slc2a4 and Fpnl was significantly decreased. Nevertheless, this upregulation of $\mathrm{Mn}$ exporters (e.g., Slc30a10, Figure $3 a, c, e, g$ and i) is not sufficient to prevent the accumulation of Mn due to the global loss of Slc39a14 expression (Figure 2a).
Hepatocyte-specific deletion of Slc39a14 expression does not lead to Mn accumulation with standard dietary $\mathrm{Mn}$

Slc39a14 is highly expressed in hepatocytes [47]. Moreover, mutations in the human SLC39A14 gene have been suggested to affect Mn transport primarily in hepatocytes, thereby underlying the parkinsonism dystonia seen in patients with such mutations; data obtained with a transgenic zebrafish model appear to support this notion [4]. To test directly whether a loss of Slc39a14 selectively in hepatocytes affects hepatic Mn uptake and causes Mn accumulation in the blood and brain, we generated hepatocyte-specific Slc39a14-

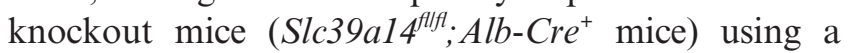
conditional knockout strategy (Figure 4a). The murine Slc39a14 gene encodes two isoforms that contain either exon $5 \mathrm{a}$ or $5 \mathrm{~b}$ [32]. We therefore targeted exon 4 , which introduces a premature stop codon in both isoforms (Figure 4a). qPCR analysis confirmed that hepatic expression of Slc39a14 was virtually abolished in Slc39al4 $4^{\text {flff }}$; Alb-Cre $e^{+}$mice compared with control mice (Figure 4b).

Unlike Slc39al4 ${ }^{-1-}$ mice, the hepatocyte-specific Slc39a14-knockout mice do not develop torticollis (data not shown), reduced body weight (Figure 4c), or neurological deficits (Figure 4d), suggesting that dysregulated $\mathrm{Mn}$ metabolism in non-hepatic tissues contributes to the phenotype in Slc39al4 ${ }^{-1-}$ mice. Moreover, consistent with the targeted deletion of Slc39a14 expression in the liver, Slc39a14 ${ }^{\text {flft }}$; $\mathrm{Alb}^{-\mathrm{Cre}^{+}}$ mice had normal levels of $\mathrm{Mn}, \mathrm{Zn}$ and $\mathrm{Cu}$ in all tissues examined (Figure $4 \mathrm{e}-\mathrm{h}$ ), with the notable exception of significantly reduced hepatic Mn levels (Figure 4e). Thus, deleting Slc39al4 expression selectively in hepatocytes does not induce systemic Mn accumulation, supporting the notion that the liver is the primary reservoir for Slc39a14-mediated Mn uptake in mice.

\section{High dietary Mn does not lead to hepatic Mn} accumulation in hepatocyte-specific Slc39al4-knockout mice

Given the systemic accumulation of $\mathrm{Mn}$ in Slc39a14 ${ }^{-1-}$ mice, and that the liver is the primary storage site for Slc39a14-mediated Mn uptake in mice, we hypothesized that feeding hepatocyte-specific Slc39a14 ${ }^{\text {flff }}$; Alb-Cre ${ }^{+}$mice a high $\mathrm{Mn}$ diet might increase their brain $\mathrm{Mn}$ levels. We therefore fed newly

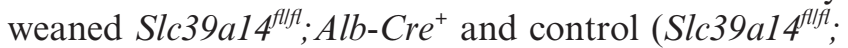
Alb-Cre ${ }^{-}$) mice a purified AIN-93G diet containing either a normal (10 p.p.m.) or high (2 400 p.p.m.) concentration of Mn [48]. After 30 days on a high Mn diet, neither body weight (Figure 5a) nor rotarod 
a

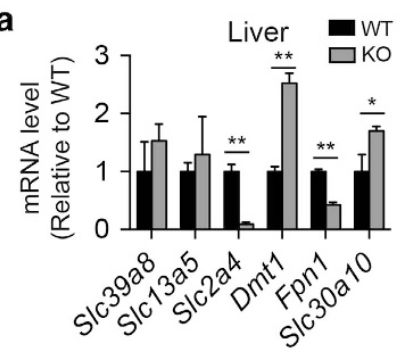

d

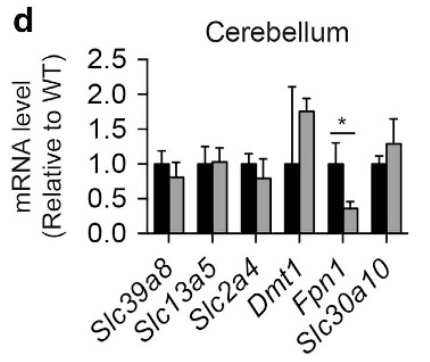

g

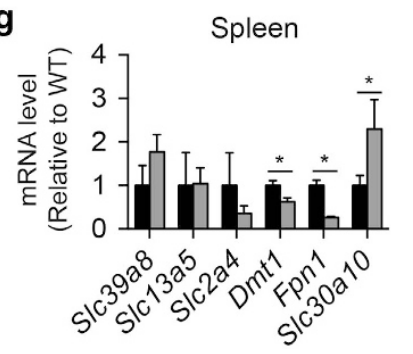

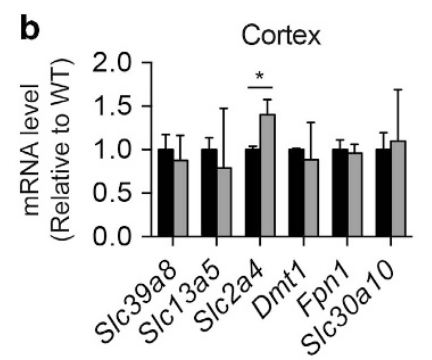

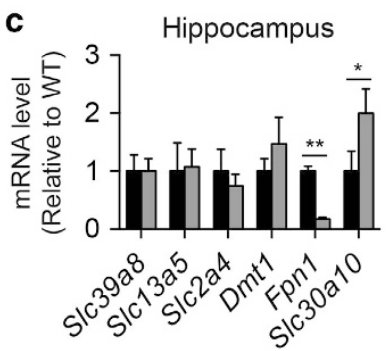

e
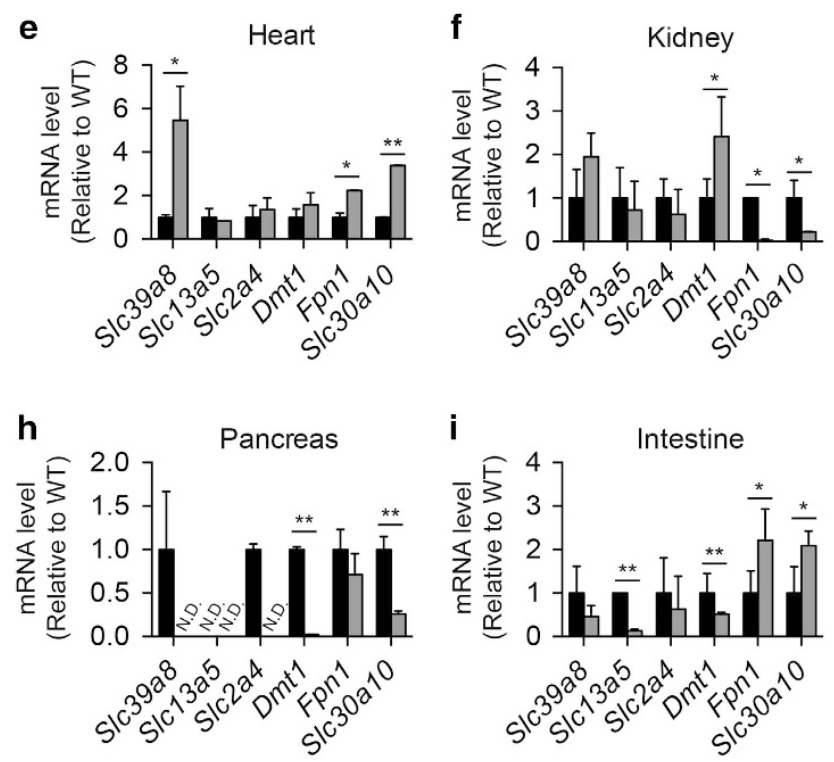

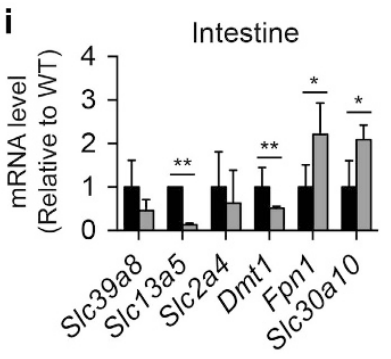

Figure 3 Expression levels of various Mn transporters in wild-type and S/c39a14 ${ }^{-/}$mice. The mRNA levels of S/c39a8, S/c13a5, Slc2a4, Dmt1, Fpn1 and Slc30a10 were measured in the liver (a), cortex (b), hippocampus (c), cerebellum (d), heart (e), kidney (f), spleen (g), pancreas (h), intestine (i) of wild-type (WT) and S/c39a14 ${ }^{-/}$(KO) mice at $>24$ weeks of age. ( $\left.n=4 \mathrm{mice} / \mathrm{group}\right)$. N.D. stands for not detected, ${ }^{*} P<0.05$ and ${ }^{* *} P<0.01$, unpaired Student's $t$-test.

performance (Figure 5b) differed between Slc39al $4^{f l f t}$; $\mathrm{Alb}-\mathrm{Cre}^{+}$and control mice; we also found no difference between mice fed a normal Mn diet and mice fed a high Mn diet (compare Figure 5a and b with Figure $4 \mathrm{c}$ and $\mathrm{d}$, respectively). However, the high $\mathrm{Mn}$ diet increased serum Mn levels in both Slc39al4 $4^{f l f t} ; \mathrm{Alb}^{-\mathrm{Cre}^{+}}$and control mice, with a much stronger effect on the Slc39a14 $4^{\text {Allf }}$; $\mathrm{Alb}-\mathrm{Cre} \mathrm{C}^{+}$mice (Figure 5c).

Interestingly, and consistent with the selective loss of Slc39a14 expression in the liver, hepatic Mn levels remained extremely low in the high $\mathrm{Mn}$-fed Slc39al $4^{\text {flft }}$; $\mathrm{Alb}-\mathrm{Cre}^{+}$mice; in these mice, hepatic Mn levels were even lower than in control mice fed a normal Mn diet (Figure 5d). In contrast, Mn levels were significantly higher in the brain (Figure 5e) and pancreas (Figure 5f) of high Mn-fed Slc39al $4^{f l f f}$; Alb-Cre ${ }^{+}$mice compared with both control mice and Slc39a14 ${ }^{\text {flff }} ; \mathrm{Alb}^{-\mathrm{Cre}^{+}}$mice fed a normal Mn diet; intestinal Mn levels were sig-

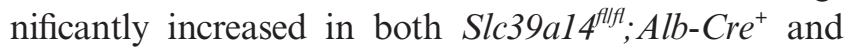

control mice, but did not differ significantly between genotypes (Figure 5g). Finally, ICP-MS measurements showed that feeding Slc39a14 ${ }^{f l f f} ; \mathrm{Alb}-\mathrm{Cre}^{+}$mice a high $\mathrm{Mn}$ diet had no significant effect on $\mathrm{Fe}, \mathrm{Zn}$ or $\mathrm{Cu}$ levels in any tissues examined.

\section{Discussion}

Here, we characterized the role of the metal ion transporter Slc39a14 in systemic Mn metabolism using both global Slc39al4-knockout and hepatocytespecific Slc39al4-knockout mice. Our results reveal that hepatic Slc39a14 has a specific role in maintaining systemic Mn homeostasis. Specifically, we found that Slc39a14 regulates Mn uptake primarily in the liver, which in turn mediates $\mathrm{Mn}$ levels in other tissues, including the brain, heart, kidney and circulation. Moreover, our results indicate that Slc39a14 functions to control the influx of $\mathrm{Mn}$ in the liver, as Slc39a14 ${ }^{-/}$ 
a

Conditional knockout

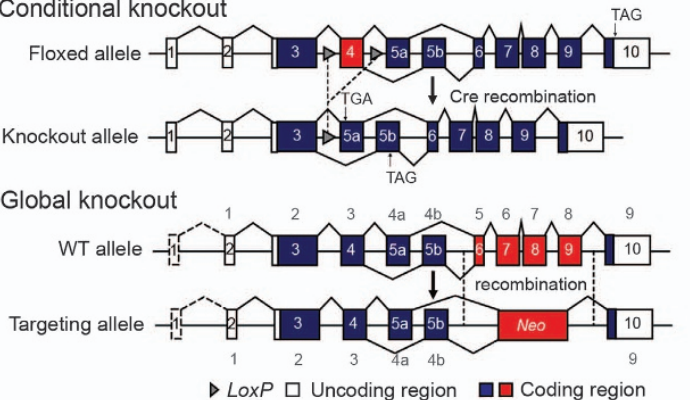

e

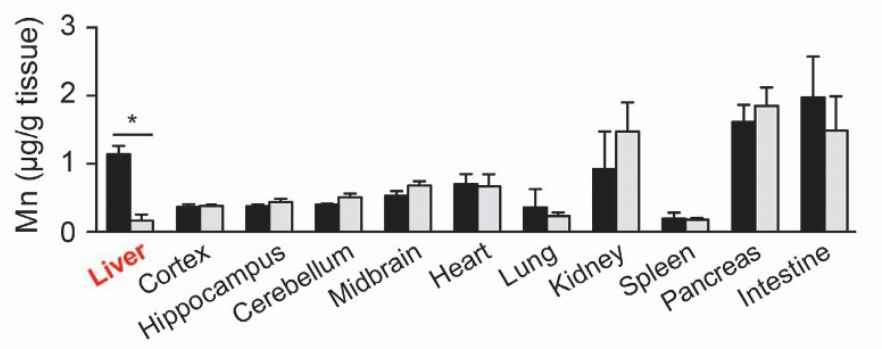

f

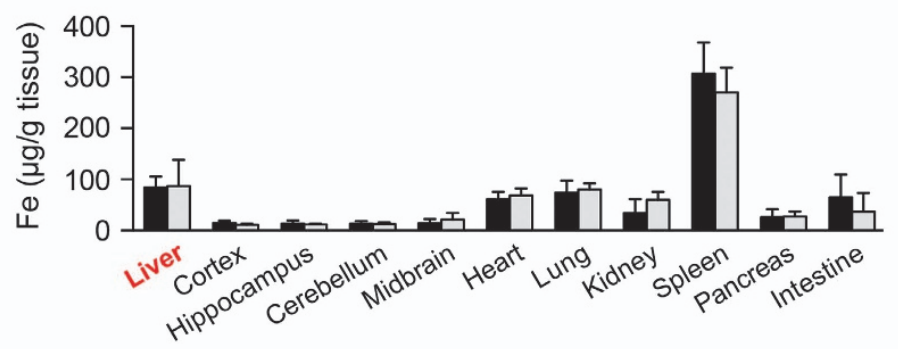

g

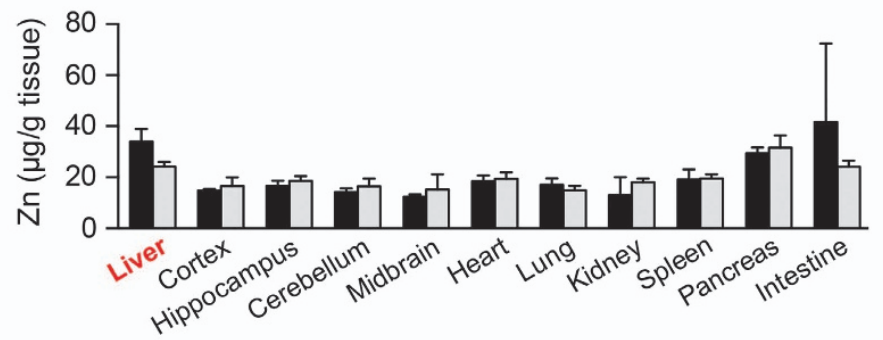

h

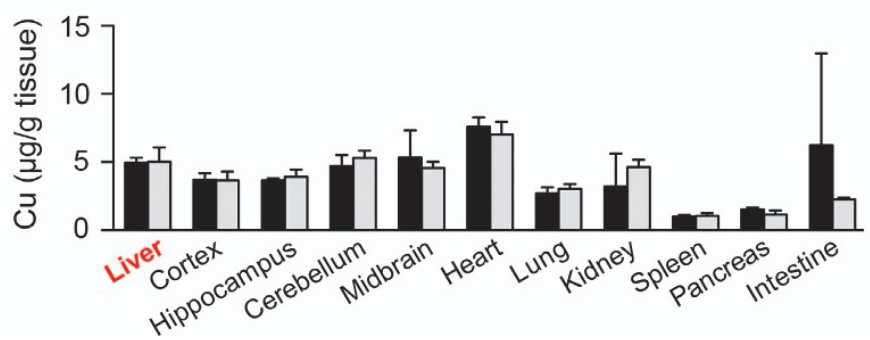

b

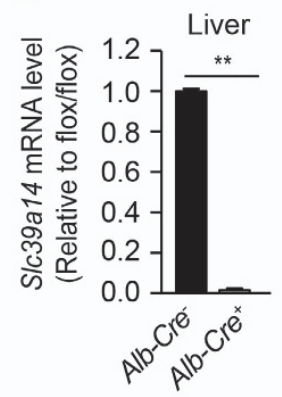

c

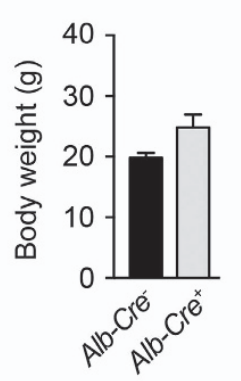

d

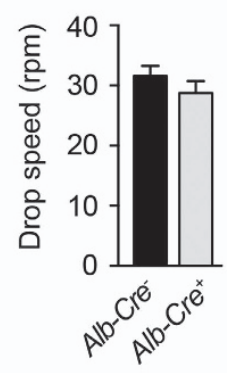

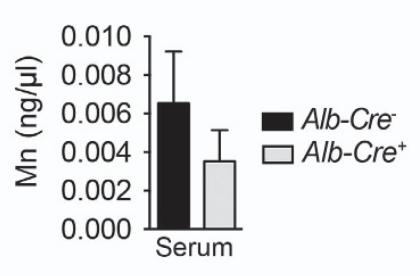

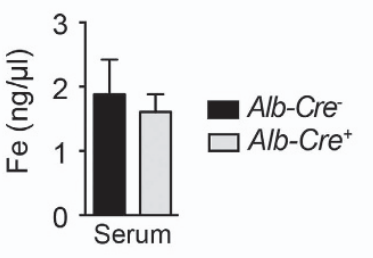

Figure 4 Hepatic Slc39a14 regulates Mn homeostasis by controlling the uptake of Mn in the liver. (a) Gene targeting strategy for generating the hepatocyte-specific Slc39a14-knockout mice (S/c39a14

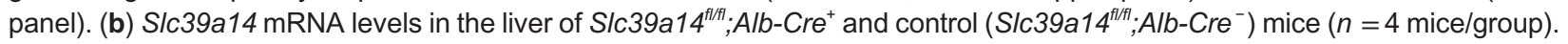
(c, d) Summary of body weight (c) and rotarod test results (d) for Slc39a14 $1 / / / / 7$;Alb-Cre ${ }^{+}$and control mice ( $n=4$ mice/group). $(\mathbf{e}-\mathbf{h})$ Levels of $\mathrm{Mn}(\mathbf{e}), \mathrm{Fe}(\mathbf{f}), \mathrm{Zn}(\mathbf{g})$ and $\mathrm{Cu}(\mathbf{h})$ were measured in the indicated tissues of S/c39a14 ${ }^{f / f t} ; A / b-C r e^{+}$and control mice at 8-12 weeks of age ( $n=3$ mice/group). ${ }^{*} P<0.05$ and ${ }^{* *} P<0.01$, unpaired Student's $t$-test. 

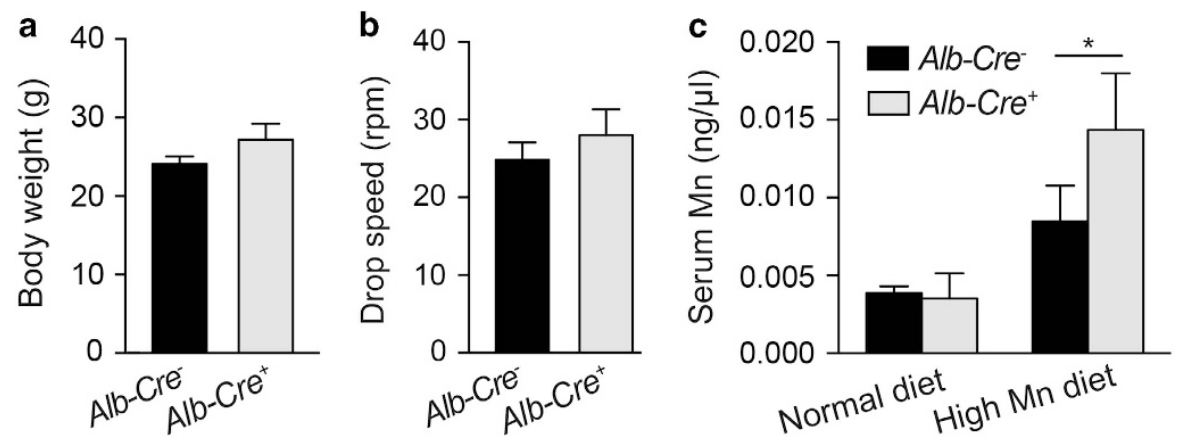

d

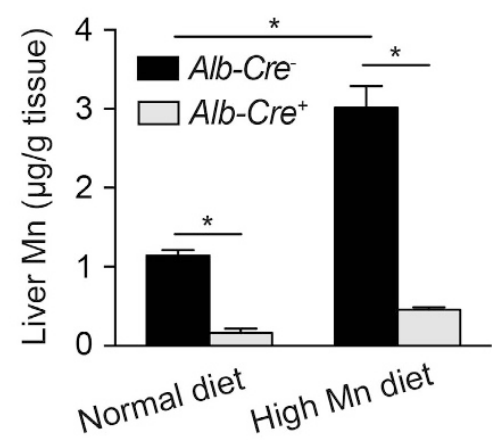

$\mathbf{f}$

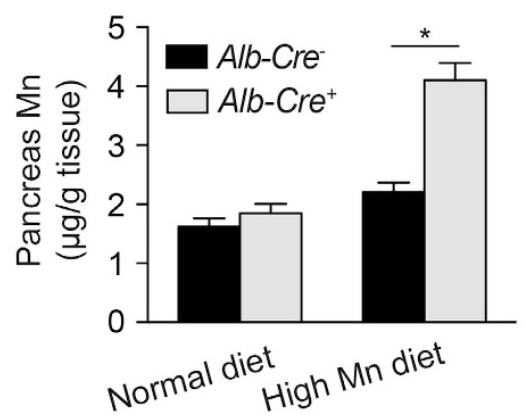

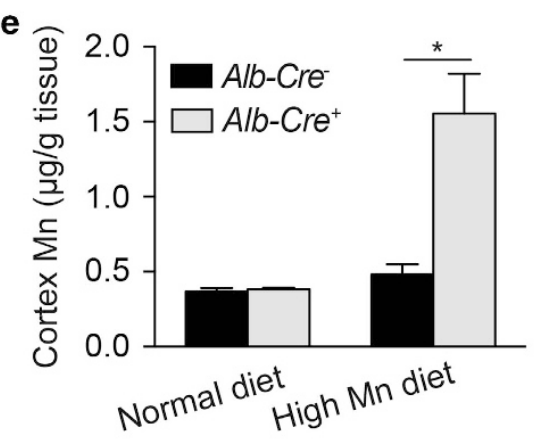

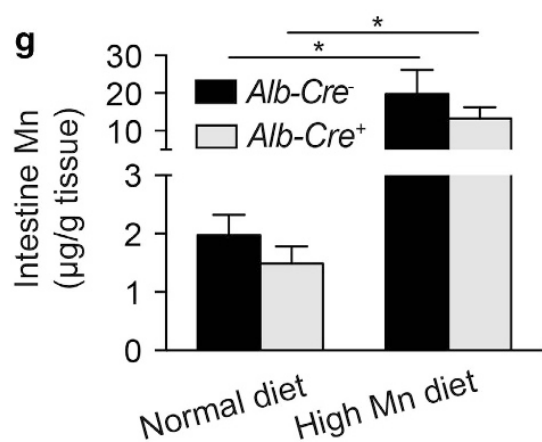

Figure 5 Summary of tissue Mn levels in hepatocyte-specific S/c39a14-knockout mice. S/c39a14 $4^{\text {th/t }}$;Alb-Cre ${ }^{+}$and control mice were fed a high Mn diet for 4 weeks. (a, b) Summary of body weight (a) and rotarod test results (b) for S/c 39 a $14^{t / 7 / f} ; A / b-C r e{ }^{+}$and control mice after consuming a high Mn diet for 4 weeks ( $n=4$ mice/group, 5 month of age). (c-g) Mn levels were measured in the

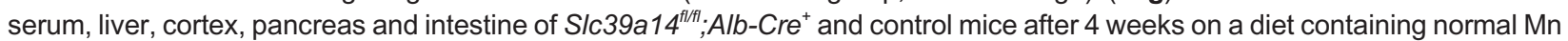
or high Mn ( $n=4-6$ mice/group, 5 month of age). In $\mathbf{c}-\mathbf{g}$, ${ }^{*} P<0.05$, one-way ANOVA with Tukey's post hoc test.

mice develop Mn accumulation in the brain and other tissues, but not in the liver. Furthermore, we found that hepatocyte-specific Slc39al4-knockout mice do not develop signs of $\mathrm{Mn}$ accumulation under normal dietary Mn conditions; however, upon consuming a high Mn diet, these mice develop increased Mn levels in the brain and serum, but not in the liver. Taken together, these findings indicate that hepatic Slc39a14 regulates $\mathrm{Mn}$ homeostasis by mediating the hepatic uptake of $\mathrm{Mn}$, providing insight into the function of SLC39A14 in humans.

Maintaining Mn homeostasis is essential for human health, and excess $\mathrm{Mn}$ has been linked to brain $\mathrm{Mn}$ accumulation and neurodegeneration [49, 50]. Mutations in the Mn transporters SLC39A14 and SLC30A10 have been associated with increased Mn levels in the serum and brain $[4,30]$ and the development of PD-like symptoms. Moreover, exposure to occupational and other environmental sources of high Mn can cause similar neurological symptoms [50, 51]. The patients with a homozygous mutation in SLC39A14 have increased levels of $\mathrm{Mn}$ in the blood and brain at an early age and develop dystoniaparkinsonism [4]. However, unlike patients with a mutation in SLC30A10, these patients do not have increased hepatic Mn levels, nor do they develop liver 
disease. In addition, Tuschl et al. deleted Slc39a14 expression in zebrafish and found increased Mn levels in the brain, but not in the abdominal viscera. In contrast, our experiments using mouse knockout models provide a causal link between SLC39A14 function, hepatic Mn import and Mn-related neurotoxicity. Unfortunately, performing these experiments in humans would not be possible.

A key finding of our study is that SLC39A14 has a central role in regulating hepatic Mn uptake. We found that selectively deleting Slc39a14 expression in hepatocytes does not cause Mn overload in the brain, blood or other tissues. In contrast, global Slc39al4-knockout mice have dysregulated $\mathrm{Mn}$ metabolism and develop behavioral and motor deficits similar to the movement disorder symptoms in patients with an SLC39A14 mutation [4]. Our analysis of hepatocyte-specific Slc39a14-knockout mice indicates that the accumulation of $\mathrm{Mn}$ in the blood and brain does not arise solely from impaired hepatic $\mathrm{Mn}$ uptake. Although Slc39a14 $4^{-1-}$ mice were previously reported to have reduced zinc uptake and increased iron absorption [31], our ICP-MS data show that Slc39a14 $4^{-1-}$ mice have normal tissue levels of $\mathrm{Fe}, \mathrm{Zn}$ and $\mathrm{Cu}$ (with the sole exception of increased serum Fe levels). Taken together, our data provide compelling evidence that globally deleting Slc39a14 expression primarily affects $\mathrm{Mn}$ metabolism, but has little effect on $\mathrm{Fe}, \mathrm{Zn}$ or $\mathrm{Cu}$ metabolism, thereby indicating that Slc39a14 functions primarily as a $\mathrm{Mn}$ transporter.

The mechanism underlying Mn toxicity is poorly understood. Although the central nervous system is a well-known primary target for $\mathrm{Mn}$, how $\mathrm{Mn}$ is transported across the blood-brain barrier is currently unknown. Based on our results, we believe that SLC39A14 does not directly mediate the uptake of Mn into the brain; rather, hepatic SLC39A14 has systemic effects on Mn homeostasis. In humans, dietary $\mathrm{Mn}$ is delivered to the liver, where it forms a conjugate with bile and is then excreted into the intestine [52, 53]. In mammals, $\mathrm{Mn}$ is excreted into the caudal parts of the intestinal tract [26]. Given that Slc39a14 is expressed on the basolateral membrane of mucosal cells in the proximal intestine [54], it is possible that Slc39a14 has a role in excreting $\mathrm{Mn}$ from the proximal intestine. In addition, our data suggest that the differences in susceptibility to $\mathrm{Mn}$ accumulation between different tissues may be attributed to different tissue distributions of the major Mn transporters.

Mn toxicity has been linked directly to behavioral and movement disorders in both humans and animal models [51, 55], and $\mathrm{Na}_{2}$ CaEDTA is often used to
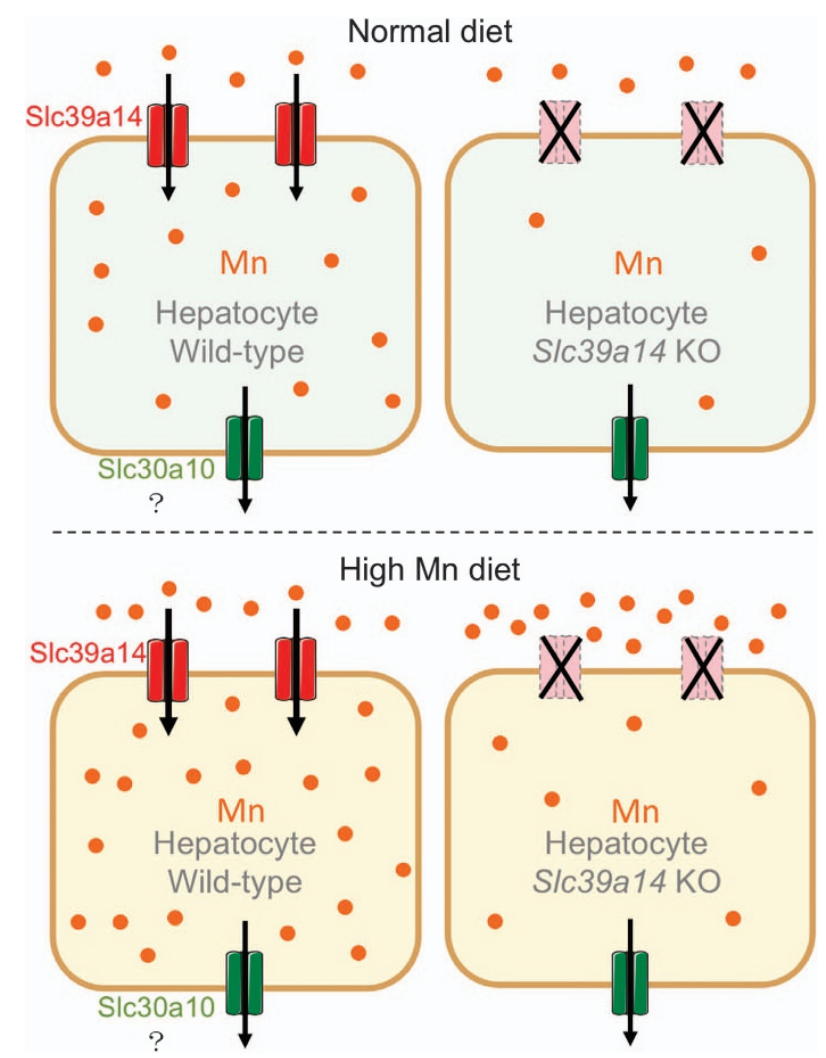

Figure 6 Schematic model depicting the role of hepatic Slc39a14 on intracellular and systemic Mn levels. (Top) Under normal dietary Mn conditions with normal Slc39a14 levels (left), Mn is absorbed by hepatocytes via the Mn transporter Slc39a14 (shown in red) and may be exported via the Mn exporter Slc30a10 (shown in green). In contrast, loss of S/c39a14 expression leads to significantly decreased $\mathrm{Mn}$ levels in hepatocytes (right). (Bottom) Consuming a high $\mathrm{Mn}$ diet fails to overcome the reduced Mn levels in S/c39a14-knockout hepatocytes, leading to increased systemic $\mathrm{Mn}$ accumulation.

chelate high levels of heavy metals, albeit with mixed results. For example, $\mathrm{Na}_{2} \mathrm{CaEDTA}$ chelation therapy reduced $\mathrm{Mn}$ load and reversed Mn-related neurotoxicity in one patient with an SLC39A14 mutation, but had no effect in another patient with the same mutation [4]. We found that Slc39al4-knockout mice develop behavioral and motor deficits associated with high levels of $\mathrm{Mn}$ in the brain, and $\mathrm{Na}_{2} \mathrm{CaEDTA}$ treatment significantly decreased serum $\mathrm{Mn}$ content and improved locomotor function in these mice.

Based on our findings, we suggest a model in which hepatic SLC39A14 has a role in maintaining systemic Mn homeostasis (Figure 6). In this model, under normal dietary $\mathrm{Mn}, \mathrm{Mn}$ is absorbed into wild-type hepatocytes via Slc39a14. If Slc39a14 expression is deleted in hepatocytes, their intracellular Mn levels are reduced 
considerably. Under high dietary Mn, intracellular Mn increases considerably in wild-type hepatocytes, but not in Slc39a14-deficient hepatocytes, regardless of extracellular Mn concentration. At the systemic level, deleting Slc39a14 expression leads to Mn accumulation in the brain and other tissues, but not in the liver, suggesting that the brain in Slc39a14 ${ }^{-/-}$mice is highly susceptible to $\mathrm{Mn}$ toxicity. On the other hand, hepatocyte-specific Slc39a14-knockout mice do not develop Mn accumulation in the brain, blood or other tissues; if challenged with a high Mn diet, however, these mice develop increased Mn levels in the brain, possibly due to the inability to sequester $\mathrm{Mn}$ in the liver. Although further studies are needed in order to determine the tissue-specific role that SLC39A14 has in $\mathrm{Mn}$ metabolism, our mouse models provide a valuable tool for investigating the underlying mechanisms by which $\mathrm{Mn}$ transporters regulate $\mathrm{Mn}$ homeostasis and for testing new pharmaceutical approaches to manage Mn toxicity in neurodegenerative diseases.

\section{Materials and Methods}

\section{Animals}

All mice were housed in a specific pathogen-free facility and maintained on a purified AIN-76A diet (Research Diets, New Brunswick, NJ, USA). All mice were maintained under a 12-hour light/dark cycle, and all animal experiments were approved by the Institutional Animal Care and Use Committee of Zhengzhou University.

Heterozygous Slc39a14 $4^{+/-}$mice [32] on a mixed background were backcrossed to C57BL6/J mice more than five generations. Slc39al $4^{+/-}$mice were then crossed to generate litters containing

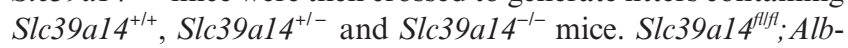
$\mathrm{Cre}^{+}$mice were generated by gene targeting ES cells in order to delete exon 4 in the Slc39al4 gene, resulting in Slc39al $4^{\mathrm{fll}+\mathrm{H}}$ mice (Shanghai Biomodel Organism, Shanghai, China). Slc39al $4^{f l+}$ mice were backcrossed to C57BL6/J mice more than seven generations, and Slc39al4 flfl mice were bred with Alb-Cre transgenic mice to generate Slc39al4 ${ }^{\text {fllf }} ; \mathrm{Alb}-\mathrm{Cre}^{+}$and Slc39al $4^{\text {flf }}$; Alb-Cre- offspring.

\section{Animal genotyping}

Genomic DNA was extracted from mouse tail biopsies using the TIANamp Genomic DNA Kit (Tiangen Biotech, Beijing, China; Cat. \#DP304). The following primer pair was used to genotype the Slc39a14 fllt mice: CTGTGGTCTTCCTGCC TTGG and TACCCTGCCCTACACGACTC; the following primer pair was used to genotype the Slc39al $4^{\text {fllfl }}$; Alb-Cre mice: GCAAACATACGCAAGGGATT and AGGCAAATTTT GGTGTACGG. To genotype the offspring from the Slc39al4 ${ }^{+/}$crosses, two forward primers (TGCTGC TGCTATTTGGGTCT or CTCGTGCTTTACGGTATCGC to amplify the wild-type and mutant alleles, respectively) were used with a single reverse primer (GAATGCTGCATT GAAAAGGTC).

\section{Behavioral testing}

To phenotype the mice in this study, we used the balance beam, accelerating rotarod and CatWalk tests. For each experiment, four pairs of knockout mice and control littermates were used. The mice were trained for three consecutive days and were tested on the fourth day. Thereafter, the tests were repeated once a week until the mice could no longer complete the tests.

For the balance beam [33, 34], a 100-cm long, 10-mm thick beam was placed at a height of $70 \mathrm{~cm}$ with an enclosed goal box at one end. During training, the mouse was allowed to acclimate to the goal box for $10 \mathrm{~min}$. The mouse was then trained to walk the beam from the starting point to the goal box. On the testing day, the time taken to travel from the starting point to the goal box was recorded.

The accelerating rotarod [35, 36] (Softmaze-XR1514, Shanghai, China) consisted of a felt-covered steel cylinder fitted to a rotating pump with a variable speed setting. Age-matched animals were trained on the rotarod for three consecutive days, with three 5-min training trials with the speed set to 10, 12 and 14 r.p.m. After these three training days, the mice were tested. During testing, the rotarod speed was increased from 4 to 40 r.p.m. over a 5-min period, and both the speed at which the mouse fell off the rod (in r.p.m.) and total running time (in seconds) were measured.

To analyze the animals' gait, we used the CatWalk XT system [37-39] (Noldus Information Technology, Wageningen, The Netherlands). To measure the gait, the mouse was placed on a glass plate and allowed to walk along a narrow walkway, with a green light on the walkway and a red ceiling light to illuminate the mouse; a camera was used to record the mouse's paw placement while walking. During the test, the mouse was placed in an enclosed box at the end of the walkway and allowed to acclimate for $10 \mathrm{~min}$, after which the lights were turned off, and the mouse was allowed to walk from the beginning of the walkway to the end of the walkway and enter the box. A successful trial was defined as the mouse taking $\leqslant 10 \mathrm{~s}$ to cross the field of vision of a video camera that was used to capture the mouse's movement, which was analyzed by CatWalk XT software based on the mouse's limbs. Each mouse successfully completed three trials on each training day and two trials on the test day.

\section{Laboratory measurements for ICP-MS detection}

These methods were performed as previously described [4, 41-43]. Approximately 10-200 mg of each organ was placed in a 25-ml PFA vial with a screw cap and digested with $3.4 \mathrm{ml}$ of concentrated EMSURE nitric acid solution $\left(65 \%, 1.39 \mathrm{~g} \mathrm{ml}^{-1}\right.$, Merck, Darmstadt, Germany). The following microwave program was used for digestion: the temperature of the sample was ramped from room temperature to 200 degrees by microwaving at $1000 \mathrm{~W}$ for $20 \mathrm{~min}$; the microwave power was then held at $1000 \mathrm{~W}$ for an additional $30 \mathrm{~min}$, followed by a 15-min cooling step. The total digestion time was therefore $65 \mathrm{~min}$. The digested samples were dried by heating and immediately diluted to a final volume of $5 \mathrm{ml}$ in high-purity deionized water $\left(18 \mathrm{M} \Omega \mathrm{cm}^{-1}\right.$ 
resistivity) obtained from a Milli-Q Integral 10 purification system (EMD Millipore Corporation, Darmstadt, Germany). Multi-element standard solutions containing $\mathrm{Mn}, \mathrm{Fe}, \mathrm{Zn}$ and $\mathrm{Cu}$ were prepared by diluting and mixing individual element standard stock solutions $\left(1000 \mu \mathrm{g} \mathrm{ml}^{-1}\right)$ obtained from the National Institute of Quality Standards (Beijing, China). An Agilent 7700x ICP-MS equipped with an Agilent ASX 520 auto-sampler was used to measure elements.

\section{$R N A$ extraction and $q P C R$ analysis}

Total RNA was extracted from the mouse tissues using TRIzol reagent (Invitrogen, Shanghai, China), and cDNA was synthesized using the PrimerScript RT reagent Kit with gDNA Eraser (Takara, Beijing, China, cat. \#RR047). Real-time PCR was performed using the two-step quantitative RT-PCR method in accordance with the manufacturer's instructions (Takara, cat. \#RR820) on a QuantStudio 7 Flex Real-Time PCR System (ThermoFisher Applied Biosystems, Waltham, MA, USA). The expression level of each target gene was normalized to the sample's Gapdh mRNA level and is expressed relative to the respective wild-type level. The following primer sets were used:

Slc39al4 forward 5'-TTTCCCAGCCCAAGGAAG-3' and reverse 5'-CAAAGAGGTCTCCAGAGCTAAA-3'; Dmt1 forward 5'-CGGGGATGAATGACTTCCTG-3' and reverse 5'-GGACATAAACCACTACAAAGTACA-3'; Slc39a8 forward 5'-TGCCTGGATGATCACGCTTT-3' and reverse 5'-CGGGTGCTCATTCCTGCAT-3'; Slc30al0 forward 5'-GCCACCTTGCACATCAAACA-3' and reverse 5'-GCT TCTTAGCGCAGCTCTGG-3'; Slc13a5 forward 5'-CAGG GCTCTCGAAGTGGATG-3' and reverse 5'-GAATCA TGACATACAGAGGATGGA-3'; $5 l c 2 a 4$ forward 5'-AAC GGGTTCCAGCCATGAG-3' and reverse 5'-AACCCAT GCCGACAATGAAG-3'; Fpnl forward 5'-GTCGGCCAG ATTATGACATTTG-3' and reverse 5'-ATTCCAACCGG AAATAAAACCA-3'.

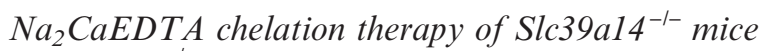

Slc39a14 $4^{-1-}$ mice received a daily i.p. injection of $370 \mathrm{mg} \mathrm{kg}^{-1}$ $\mathrm{Na}_{2} \mathrm{CaEDTA}$ (disodium calcium edetate, also known as edetate calcium disodium, ethylene diamine tetra-acetic acid disodium calcium salt) [44, 45] for four days, followed by three days without injection. After four weeks of this weekly treatment cycle, performance on the rotarod test was measured.

\section{Dietary Mn supplementation in hepatocyte-specific Slc39a14-knockout mice}

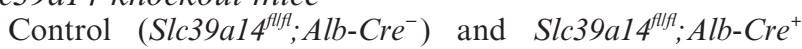
mice were fed a purified AIN-93G diet containing either normal (10 p.p.m.) Mn (diet D08080401) or high (2 400 p.p.m.) Mn (diet D17020702) for 30 days. Based on a previous study, 2400 p.p.m. of dietary Mn does not induce toxicity [48]. During the 30-day feeding period, body weight, motor performance and ICP-MS metal analysis were performed as described above.

\section{Statistical analysis}

At least three independent experiments were used for statistical analyses. GraphPad Prism 5 software was used for statistical analyses, and all data passed the test for normality.
Multiples groups were analyzed using a one-way ANOVA with Tukey's post hoc test, and differences between two groups were analyzed using the Student's $t$-test. Differences with a $P$-value $<0.05$ were considered significant. All summary data are presented as the mean \pm s.e.m.

\section{Conflict of Interest}

The authors declare no conflict of interest.

\section{Acknowledgements}

We thank Ms. Xiaoyu Chen for the management of the animal facility and animal care. We also thank Mr. Qingtang Fan for video capture and editing. This work was supported by research grants from the National Natural Science Foundation of China (31530034, 31330036 and 31225013 to FW), the Natural Science Foundation of Henan Province (162300410267 to HZ), and Research Supporting Funds from Zhengzhou University. We thank the members of the Wang and Min Laboratories for helpful discussions.

\section{Author contributions}

YX, HG and FW designed the project. YX and YQ performed most of the experiments. JW, HL, CS and YX assisted with the behavioral testing and data analyses. JW and HZ assisted with the ICP-MS analyses. YX, LY, RZ and HW preformed the qPCR and data analysis. $\mathrm{HG}, \mathrm{SH}$ and $\mathrm{TF}$ generated the Slc39a14 ${ }^{-1-}$ knockout mice, and YY and YQ helped with the animal experiments. The manuscript was written by YX, HG, UI, JM and FW.

\section{References}

1 Ward RJ, Zucca FA, Duyn JH, Crichton RR, Zecca L. The role of iron in brain ageing and neurodegenerative disorders. Lancet Neurol 2014; 13: 1045-1060.

2 Stys PK, Zamponi GW, van Minnen J, Geurts JJ. Will the real multiple sclerosis please stand up? Nat Rev Neurosci 2012; 13: 507-514.

3 Weekley CM, He C. Developing drugs targeting transition metal homeostasis. Curr Opin Chem Biol 2016; 37: 26-32.

4 Tuschl K, Meyer E, Valdivia LE et al. Mutations in SLC39A14 disrupt manganese homeostasis and cause childhood-onset parkinsonism-dystonia. Nat Commun 2016; 7: 11601.

5 Aschner JL, Aschner M. Nutritional aspects of manganese homeostasis. Mol Aspects Med 2005; 26: 353-362.

6 Roth JA. Correlation between the biochemical pathways altered by mutated parkinson-related genes and chronic exposure to manganese. Neurotoxicology 2014; 44: 314-325.

7 Keen CL, Baly DL, Lonnerdal B. Metabolic effects of high doses of manganese in rats. Biol Trace Elem Res 1984; 6: 309-315.

8 Salazar J, Mena N, Hunot S et al. Divalent metal transporter 1 (DMT1) contributes to neurodegeneration in 
animal models of Parkinson's disease. Proc Natl Acad Sci USA 2008; 105: 18578-18583.

9 Garrick MD, Singleton ST, Vargas F et al. DMT1: which metals does it transport? Biol Res 2006; 39: 79-85.

10 Crossgrove JS, Yokel RA. Manganese distribution across the blood-brain barrier. IV. Evidence for brain influx through store-operated calcium channels. Neurotoxicology 2005; 26: 297-307.

11 Chua AC, Morgan EH. Manganese metabolism is impaired in the Belgrade laboratory rat. J Comp Physiol B 1997; 167: 361-369.

12 Mitchell CJ, Shawki A, Ganz T, Nemeth E, Mackenzie B. Functional properties of human ferroportin, a cellular iron exporter reactive also with cobalt and zinc. Am $J$ Physiol Cell Physiol 2014; 306: C450-C459.

13 Lin W, Vann DR, Doulias PT et al. Hepatic metal ion transporter ZIP8 regulates manganese homeostasis and manganese-dependent enzyme activity. J Clin Invest 2017; 127: 2407-2417.

14 Park JH, Hogrebe M, Gruneberg M et al. SLC39A8 deficiency: a disorder of manganese transport and glycosylation. Am J Hum Genet 2015; 97: 894-903.

15 Tuschl K, Clayton PT, Gospe SM Jr. et al. Syndrome of hepatic cirrhosis, dystonia, polycythemia, and hypermanganesemia caused by mutations in SLC30A10, a manganese transporter in man. Am J Hum Genet 2016; 99: 521.

16 Hutchens S, Liu C, Jursa T et al. Deficiency in the manganese efflux transporter SLC30A10 induces severe hypothyroidism in mice. J Biol Chem 2017; 292: 9760-9773.

17 Xia Z, Wei J, Li Y et al. Zebrafish slc30a10 deficiency revealed a novel compensatory mechanism of atp2c1 in maintaining manganese homeostasis. PLoS Genet 13(7): e1006892. https://doi.org/10.1371/journal.pgen.1006892.

18 Roth JA. Homeostatic and toxic mechanisms regulating manganese uptake, retention, and elimination. Biol Res 2006; 39: 45-57.

19 Chen P, Bowman AB, Mukhopadhyay S, Aschner M. SLC30A10: a novel manganese transporter. Worm 2015; 4: e1042648.

20 Zogzas CE, Aschner M, Mukhopadhyay S. Structural elements in the transmembrane and cytoplasmic domains of the metal transporter SLC30A10 are required for its manganese efflux activity. J Biol Chem 2016; 291: 15940-15957.

21 Gunter TE, Gerstner B, Gunter KK et al. Manganese transport via the transferrin mechanism. Neurotoxicology 2013; 34: 118-127.

22 Ponka P, Lok CN. The transferrin receptor: role in health and disease. Int J Biochem Cell Biol 1999; 31: 1111-1137.

23 Ding D, Salvi R, Roth JA. Cellular localization and developmental changes of Zip8, Zip14 and transferrin receptor 1 in the inner ear of rats. Biometals 2014; 27: 731-744.

24 Fujishiro H, Yoshida M, Nakano Y, Himeno S. Interleukin6 enhances manganese accumulation in SH-SY5Y cells: implications of the up-regulation of ZIP14 and the downregulation of ZnT10. Metallomics 2014; 6: 944-949.

25 Burnett WT Jr., Bigelow RR, Kimball AW, Sheppard CW. Radio-manganese studies on the mouse, rat and pancreatic fistula dog. Am J Physiol 1952; 168: 620-625.
26 Cotzias GC, Papavasiliou PS. Primordial Homeostasis in a mammal as shown by the control of manganese. Nature 1964; 201: 828-829.

27 Bertinchamps AJ, Miller ST, Cotzias GC. Interdependence of routes excreting manganese. Am J Physiol 1966; 211: 217-224.

28 Eide DJ. Zinc transporters and the cellular trafficking of zinc. Biochim Biophys Acta 2006; 1763: 711-722.

29 Boycott KM, Beaulieu CL, Kernohan KD et al. Autosomal-recessive intellectual disability with cerebellar atrophy syndrome caused by mutation of the manganese and zinc transporter gene SLC39A8. Am J Hum Genet 2015; 97: 886-893.

30 Leyva-Illades D, Chen P, Zogzas CE et al. SLC30A10 is a cell surface-localized manganese efflux transporter, and parkinsonism-causing mutations block its intracellular trafficking and efflux activity. $J$ Neurosci 2014; 34: 14079-14095.

31 Aydemir TB, Chang SM, Guthrie GJ et al. Zinc transporter ZIP14 functions in hepatic zinc, iron and glucose homeostasis during the innate immune response (endotoxemia). PLoS ONE 2012; 7: e48679.

32 Hojyo S, Fukada T, Shimoda S et al. The zinc transporter SLC39A14/ZIP14 controls G-protein coupled receptormediated signaling required for systemic growth. PLoS ONE 2011; 6: e18059.

33 De Munter S, Verheijden S, Vanderstuyft E et al. Earlyonset Purkinje cell dysfunction underlies cerebellar ataxia in peroxisomal multifunctional protein-2 deficiency. Neurobiol Dis 2016; 94: 157-168.

34 Unichenko P, Kirischuk S, Yang JW et al. Plasticity-related gene 1 affects mouse barrel cortex function via strengthening of glutamatergic thalamocortical transmission. Cereb Cortex 2016; 26: 3260-3272.

35 Hermann DM, Zechariah A, Kaltwasser B et al. Sustained neurological recovery induced by resveratrol is associated with angioneurogenesis rather than neuroprotection after focal cerebral ischemia. Neurobiol Dis 2015; 83: $16-25$.

36 Zhang X, Li Y, Liu C et al. Alteration of enteric monoamines with monoamine receptors and colonic dysmotility in 6-hydroxydopamine-induced Parkinson's disease rats. Transl Res 2015; 166: 152-162.

37 Song Q, Deng Y, Yang X et al. Manganese-disrupted interaction of dopamine D1 and NMDAR in the striatum to injury learning and memory ability of mice. Mol Neurobiol 2016; 53: 6745-6758.

38 Vandeputte C, Taymans JM, Casteels C et al. Automated quantitative gait analysis in animal models of movement disorders. BMC Neurosci 2010; 11: 92.

39 Westin JE, Janssen ML, Sager TN, Temel Y. Automated gait analysis in bilateral parkinsonian rats and the role of L-DOPA therapy. Behav Brain Res 2012; 226: 519-528.

40 Jenkitkasemwong S, Wang CY, Coffey R et al. SLC39A14 is required for the development of hepatocellular iron overload in murine models of hereditary hemochromatosis. Cell Metab 2015; 22: 138-150. 
41 Nisse C, Tagne-Fotso R, Howsam M, Richeval C, Labat L, Leroyer A. Blood and urinary levels of metals and metalloids in the general adult population of Northern France: The IMEPOGE study, 2008-2010. Int J Hyg Environ Health 2016; 220: 341-363.

42 Yedomon B, Menudier A, Etangs FL et al. Biomonitoring of 29 trace elements in whole blood from inhabitants of Cotonou (Benin) by ICP-MS. J Trace Elem Med Biol 2016; http://dx.doi.org/10.1016/j.jtemb.2016.11.004.

43 Sun L, Yu Y, Huang T et al. Associations between ionomic profile and metabolic abnormalities in human population. PLoS ONE 2012; 7: e38845.

44 Domingo JL, Llobet JM, Corbella J. Protection of mice against the lethal effects of sodium metavanadate: a quantitative comparison of a number of chelating agents. Toxicol Lett 1985; 26: 95-99.

45 Jones MM, Basinger MA, Gale GR, Atkins LM, Smith AB, Stone A. Effect of chelate treatments on kidney, bone and brain lead levels of lead-intoxicated mice. Toxicology 1994; 89: 91-100.

46 Tuschl K, Mills PB, Clayton PT. Manganese and the brain. Int Rev Neurobiol 2013; 110: 277-312.

47 Liuzzi JP, Aydemir F, Nam H, Knutson MD, Cousins RJ. Zip14 (Slc39a14) mediates non-transferrin-bound iron uptake into cells. Proc Natl Acad Sci USA 2006; 103: 13612-13617.

48 Sato I, Matsusaka N, Kobayashi H, Nishimura Y. Effects of dietary manganese contents on 54Mn metabolism in mice. J Radiat Res 1996; 37: 125-132.

49 Chen P, Chakraborty S, Mukhopadhyay S et al. Manganese homeostasis in the nervous system. J Neurochem 2015; 134: 601-610.

50 Martinez-Finley EJ, Gavin CE, Aschner M, Gunter TE. Manganese neurotoxicity and the role of reactive oxygen species. Free Radic Biol Med 2013; 62: 65-75.
51 Peres TV, Schettinger MR, Chen $\mathrm{P}$ et al. Manganeseinduced neurotoxicity: a review of its behavioral consequences and neuroprotective strategies. BMC Pharmacol Toxicol 2016; 17: 57.

52 Davis CD, Zech L, Greger JL. Manganese metabolism in rats: an improved methodology for assessing gut endogenous losses. Proc Soc Exp Biol Med 1993; 202: 103-108.

53 Malecki EA, Radzanowski GM, Radzanowski TJ, Gallaher DD, Greger JL. Biliary manganese excretion in conscious rats is affected by acute and chronic manganese intake but not by dietary fat. J Nutr 1996; 126: 489-498.

54 Guthrie GJ, Aydemir TB, Troche C, Martin AB, Chang SM, Cousins RJ. Influence of ZIP14 (slc39A14) on intestinal zinc processing and barrier function. $\mathrm{Am}$ J Physiol Gastrointest Liver Physiol 2015; 308: G171-G178.

55 Taba P. Metals and movement disorders. Curr Opin Neurol 2013; 26: 435-441.

(Supplementary information is linked to the online version of the paper on the Cell Discovery website).

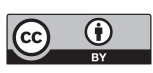

This work is licensed under a Creative Commons Attribution 4.0 International License. The images or other third party material in this article are included in the article's Creative Commons license, unless indicated otherwise in the credit line; if the material is not included under the Creative Commons license, users will need to obtain permission from the license holder to reproduce the material. To view a copy of this license, visit http://creativecommons.org/licenses/by/4.0/

(C) The Author(s) 2017 